\title{
Signature of ionospheric irregularities under different geophysical conditions on SBAS performance in the western African low-latitude region
}

\author{
Oladipo Emmanuel Abe ${ }^{1,2}$, Xurxo Otero Villamide ${ }^{1}$, Claudia Paparini ${ }^{1}$, Rodrigue Herbert Ngaya ${ }^{1}$, \\ Sandro M. Radicella ${ }^{1}$, and Bruno Nava ${ }^{1}$ \\ ${ }^{1}$ The Abdus Salam International Centre for Theoretical Physics (ICTP), Trieste, Italy \\ ${ }^{2}$ Department of Physics, Federal University Oye-Ekiti, Oye-Ekiti, Ekiti State, Nigeria
}

Correspondence to: Oladipo Emmanuel Abe (oabe@ictp.it, oladipo.abe@ fuoye.edu.ng)

Received: 29 April 2016 - Revised: 5 December 2016 - Accepted: 8 December 2016 - Published: 3 January 2017

\begin{abstract}
Rate of change of TEC (ROT) and its index (ROTI) are considered a good proxy to characterize the occurrence of ionospheric plasma irregularities like those observed after sunset at low latitudes. SBASs (satellite-based augmentation systems) are civil aviation systems that provide wide-area or regional improvement to single-frequency satellite navigation using GNSS (Global Navigation Satellite System) constellations. Plasma irregularities in the path of the GNSS signal after sunset cause severe phase fluctuations and loss of locks of the signals in GNSS receiver at low-latitude regions. ROTI is used in this paper to characterize plasma density ionospheric irregularities in central-western Africa under nominal and disturbed conditions and identified some days of irregularity inhibition. A specific low-latitude algorithm is used to emulate potential possible SBAS message using real GNSS data in the western African low-latitude region. The performance of a possible SBAS operation in the region under different ionospheric conditions is analysed. These conditions include effects of geomagnetic disturbed periods when SBAS performance appears to be enhanced due to ionospheric irregularity inhibition. The results of this paper could contribute to a feasibility assessment of a European Geostationary Navigation Overlay System-based SBAS in the sub-Saharan African region.
\end{abstract}

Keywords. Radio science (space and satellite communication)

\section{Introduction}

Ionosphere and its variability have a measurable impact on L-band radio frequencies in which GNSS and its augmentation system (satellite-based augmentation system - SBAS) belong. Strong ionospheric gradient and plasma irregularities, regularly observed after sunset in equatorial ionization anomaly (EIA) regions, are a treat to the accuracy and availability of the SBAS in the regions. Plasma irregularities in the path of the GNSS signals after sunset could cause severe amplitude and phase fluctuations, and in some cases loss of locks of the GNSS signals at the receivers' ends. This potential effect could increase the dilution of precision, i.e affect user-GNSS geometry, and thereby reduces the number of GNSS satellites that could monitor the IGP (ionospheric grid point), and consequentially degrades the SBAS optimum performance. The ionospheric plasma irregularities manifest themselves in many ways: patches, bite-outs, equatorial plasma bubbles (EPBs), equatorial spread $\mathrm{F}$ (ESF), scintillation, plume, depletions of plasma density (Handerson et al., 2005), depending on the instrument used - such as radars, ionosondes, airglows, and satellites probes (rockets, GNSS, and so on). The effect on each instrument depends on the scale size of the irregularities. Perkins (1975) described ionospheric irregularities as small-scale structures in the equatorial ionosphere, which is generally oriented to rapid plasma density fluctuation across the geomagnetic field. All the frequencies bands in the range of high frequency, very high frequency, ultra high frequency and low frequency suffer the effect of ionospheric irregularities, and the intensity of the effect decreases with the increase in frequency. It is criti- 
cal in the low-latitude and the equatorial ionization anomaly region and in high latitudes and not serious in middle latitudes. Many scientists (Chandran and Rastogi, 1972; Fejer and Kelley, 1980; Fejer et al., 1999; Lee et al., 2005; Huang et al., 2002; Manju et al., 2007; Nava et al. 2015) have associated plasma irregularities with solar and geomagnetic activities, seasons, and geographic locations. As an example, the threshold drift velocity for the generation of strong early night irregularities increases linearly with solar flux (Fejer et al., 1999). Plasma density irregularities after sunset, and sometimes to post-midnight, can be responsible for significant disruption to radio communication and navigation systems (Stoneback and Heelis, 2014).

Before the successful implementation of the American regional SBAS known as Wide Area Augmentation System (WAAS), Japan MTSAT Satellite Augmentation System (MSAS), European Geostationary Navigation Overlay System (EGNOS), and Indian GPS Aided GEO Augmented Navigation (GAGAN) system, a lot of preliminary ionospheric studies were done in selecting a suitable ionospheric correction algorithm. The ionospheric correction algorithm of the first two SBASs (WAAS and EGNOS) is based on a single-shell layer approach, while the GAGAN ionospheric algorithm uses a multi-shell layer approach. The reason is that a large percentage of landmass of the Indian subcontinent falls on the crest of the equatorial ionization anomaly (EIA) region (Sarma et al., 2006, 2009; Venkata Ratnam et al., 2009, 2011). The multi-shell layer algorithm caters to the effect of the strong ionospheric vertical drift and strong ionospheric gradients, a common feature of the crest of EIA (Suryanarayana Rao, 2007).

Although much research on the occurrences of equatorial ionospheric plasma irregularities in affecting SBAS performances has been done extensively in the American and Asian sectors, including the Indian subcontinent (2000; Rama Rao et al., 2006; Walter et al., 2007; Pandya et al. 2007; Sparks et al., 2011; Seo et al., 2011; Sunda et al., 2013), a welldefined study on the occurrences of plasma irregularities and its effect on SBAS performance in the low-latitude African sector, where the ionosphere is more turbulent compared to the Indian subcontinent, is still lacking. The reason could be because to date there is no operational SBAS in the region and the GNSS ground observations are limited in a way.

This study presents the analysis of the impact of ionospheric plasma irregularities on the performance of a possible SBAS in the western African low-latitude region using experimental data obtained from the region. Furthermore, a detail study was carried out to investigate the period of strong occurrences of ionospheric plasma irregularities during two well-known equinoctial periods and the transition months to equinoctial periods (February and August) as well as transition periods from equinoctial months (May and November). The study uses an SBAS simulator containing a specific single-shell-layer ionospheric correction algorithm. In this study, rate of change of TEC index (ROTI) is use to char- acterize the occurrence of the ionospheric plasma irregularities. Details of the SBAS simulator and the ROTI procedures are expressed in Sect. 2.

\section{Data source and analysis}

In order to evaluate the effect ionospheric plasma irregularities in the western African equatorial region on SBAS performance, the $30 \mathrm{~s}$ intervals of ground-based GNSS data from the IGS (International GNSS Services) network and other publicly available networks (AFREF, NIGNET, SONEL) of the stations over the region are used. The characteristic months of the equinoctial seasons and the transition months to equinoctial periods (February and August) and from equinoctial periods (May and November) of year 2013 as shown in Table 1 are considered. These periods are known to have a high occurrence of ionospheric plasma variability in western Africa (Ouattara et al., 2012; Zoundi et al., 2012; Abe et al., 2013). The spatial distribution of the GNSS ground-based receiver stations used with respect to the magnetic equator is given in Fig. 1. ROTI (rate of change of TEC index) is estimated over these stations in order to measure the intensity of plasma irregularities encountered by the GNSS signals passing through the region (Eqs. 1 and 2). To avoid multipath and some errors associated with tropospheric influences, satellites whose elevation mask angle is $\geq 30^{\circ}$ are considered in the ROTI estimate. ROTI has been established to be a proxy for ionospheric irregularities (Pi et al., 1997; Jiyun et al., 2006; Basu et al., 1999). Pi et al. (1997) defined ROTI as a GPS-based index that characterizes the severity of the fluctuations and detects the presence of ionospheric irregularities and irregular structure of the TEC spatial gradient. The ionospheric plasma irregularity-inhibited days are obtained following the Nishioka et al. (2008) proposal. Ionospheric plasma irregularities are assumed inhibited when the difference between nighttime (18:00-24:00 LT) ROTI and daytime (06:00-18:00 LT) ROTI (Eq. 3) is less than or equal

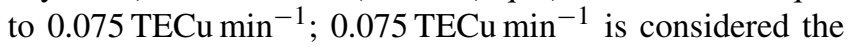
threshold for the occurrences of ionospheric irregularities being the statistical daytime mean noise of ROTI obtained over the region. The details of the inhibited days are given in Table 1 , including the geomagnetic activity index characterizing each day. The inhibited days are categorized into two geomagnetic conditions using Ap index: geomagnetically quiet and disturbed conditions. Quiet conditions are when the daily average of $A p \geq 15 \mathrm{nT}$, and disturbed conditions are when the daily average of $A p \geq 15 \mathrm{nT}$. The critical period in terms of presence of ionospheric plasma irregularities is equinoctial months (Abdu et al., 1981; Tsunoda, 1985) and some months that are before or after the equinoctial months.

To illustrate the effect of the ionospheric plasma irregularities on SBAS performance in central-western African equatorial and low-latitude region, the $30 \mathrm{~s}$ interval data rates are interpolated to $1 \mathrm{~s}$ intervals, the SBAS data format, us- 


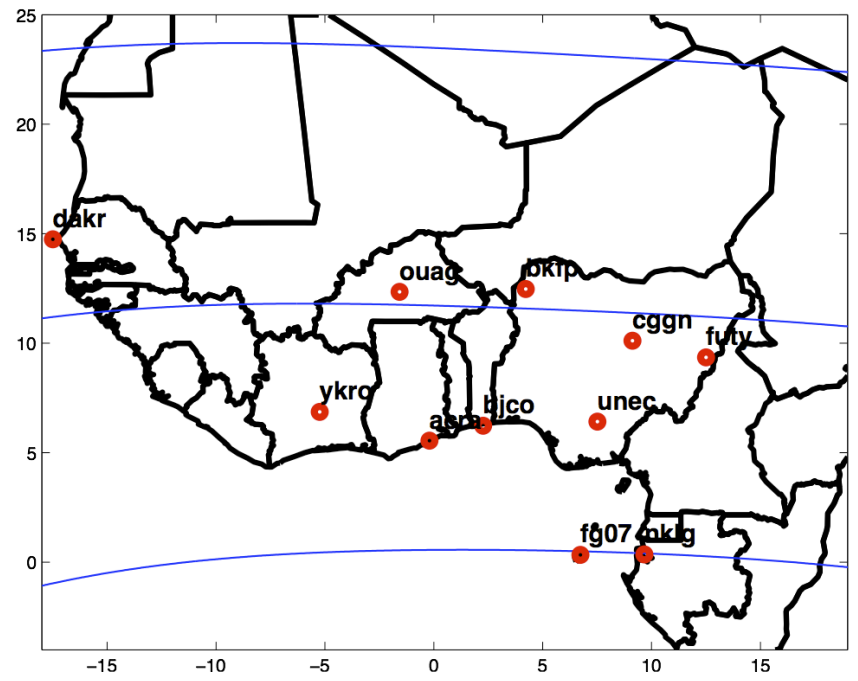

Figure 1. Distributions of GNSS receivers over central-western African equatorial and low-latitude region.

ing the Lagrange interpolation method and processed with a specific algorithm of magicSBAS platform. The Lagrange interpolation is a polynomials-based interpolation technique that gives non-monotonous outputs. Details can be obtained in Jeffreys and Jeffreys (1988). magicSBAS is a state-ofthe-art, multi-constellation, operational SBAS test bed developed by GMV. It implements real wide-area correction algorithms, and the SBAS augmentation message produced by magicSBAS is compliant with SBAS international standards such as RTCA/DO-229D and International Civil Aviation Organization (ICAO) Standard And Recommended Practices (SARPs) (Cezón et al., 2014). It is important to stress that specific version of magicSBAS algorithm optimizes the SBAS performance in low latitudes. Details of magicSBAS can be obtained from Cezón et al. (2014). An availability map of operational approach with vertical guidance and first level of service (APV-I) (one of the outputs of magicSBAS) is defined as the percentage of epochs in which the protection level is below alert limits. For this, the APV-I service horizontal protection level (HPL) is $<40 \mathrm{~m}$ and vertical protection level (VPL) is $<50 \mathrm{~m}$ over the total period of the epoch (ICAO, 2001). Quality of service (QoS), user differential range error indicator (UDREi), open service geometry availability map for signal in space, and a positional dilution of precision are considered in evaluating the SBAS performance. However, more focus was on QoS, which is the combined arithmetic average of SBAS horizontal and vertical protection levels within the service area, and it is estimated at every epoch in metres. Moreover, the parameter guarantees the safety of the SBAS user at any point in time for critical applications. To follow the aim of the study, mean of nighttime (18-24h) SBAS QoS is used.

A statistical analysis was done to understand the level of interrelationship between plasma irregularities and QoS, as
Table 1. Summary ionospheric irregularities and QoS during difference geomagnetic activities.

\begin{tabular}{lrrrl}
\hline DOY 2013 & $\begin{array}{r}\text { ROTI }_{\text {diff }} \\
\left(\text { TECu min }^{-1}\right)\end{array}$ & QoS (m) & Ap (nT) & $\begin{array}{l}\text { Geomagnetic } \\
\text { conditions }\end{array}$ \\
\hline 47 (16 Feb) & 0.006 & 5.81 & 8.0 & Quiet \\
60 (1 Mar) & 0.013 & 6.18 & 34.1 & Disturbed \\
76 (17 Mar) & 0.048 & 7.99 & 72.0 & Disturbed \\
86 (27 Mar) & 0.029 & 7.40 & 20.1 & Disturbed \\
88 (29 Mar) & 0.009 & 7.04 & 28.1 & Disturbed \\
106 (16 Apr) & 0.046 & 7.49 & 3.0 & Quiet \\
135 (15 May) & 0.072 & 7.94 & 8.0 & Quiet \\
151 (31 May) & 0.047 & 7.05 & 9.0 & Quiet \\
222 (10 Aug) & 0.073 & 4.38 & 5.0 & Quiet \\
227 (15 Aug) & 0.037 & 4.72 & 14.0 & Quiet \\
267 (24 Sep) & 0.065 & 6.77 & 12.0 & Quiet \\
287 (14 Oct) & 0.001 & 5.14 & 18.1 & Disturbed \\
311 (7 Nov) & 0.034 & 5.39 & 12.0 & Quiet \\
313 (9 Nov) & 0.030 & 5.49 & 22.0 & Disturbed \\
327 (23 Nov) & 0.040 & 7.05 & 8.0 & Quiet \\
\hline
\end{tabular}

well as to establish the level of dependency between the plasma irregularities and SBAS in central-western African equatorial and low-latitude region.

$$
\begin{aligned}
\text { ROT } & =\frac{\text { TEC }_{k}^{i}-\mathrm{TEC}_{k-1}^{i}}{t_{k}-t_{k-1}} \\
\text { ROTI } & =\sqrt{<\text { ROT }^{2}>-<\text { ROT }^{2}} \\
\text { ROTI }_{\text {diff }} & =\operatorname{ROTI}_{[18-24]}-\operatorname{ROTI}_{[6-18]},
\end{aligned}
$$

where $i$ is the visible satellite and $k$ is the time of epoch, TEC is the total electron content, ROT is the rate of change of TEC and ROTI is the change of change of TEC index ( $5 \mathrm{~min}$ standard deviation of ROT at a sampling interval of $30 \mathrm{~s}$ ).

\section{Results and discussion}

Figure 2 presents the correspondence of ionospheric plasma irregularities (as measured by ROTI) with SBAS QoS obtained in central-western African low-latitude and equatorial region for the months of January and April 2013. The month of January represents December solstitial season, while April represents March equinoctial season. The figure shows that occurrences of ionospheric plasma irregularities are very low throughout the month of January, which translates to good performance in SBAS as expressed by the value of QoS being less than $10 \mathrm{~m}$ throughout the month. However, a contrary incident was recorded during the month of April; the ionospheric plasma irregularities are very strong except day 16 . The month of April is an equinoctial month in which the magnetic meridian is closely aligned with the solar terminator (Abdu et al., 1981; Tsunoda, 1985; Bhattacharya et al., 2010; Tanna et al., 2013). Lowering/inhibition of ionospheric plasma irregularities is unique and of great interest. Therefore the performance of the SBAS simulated over the central-western African low-latitude region as indicated by 
(a)
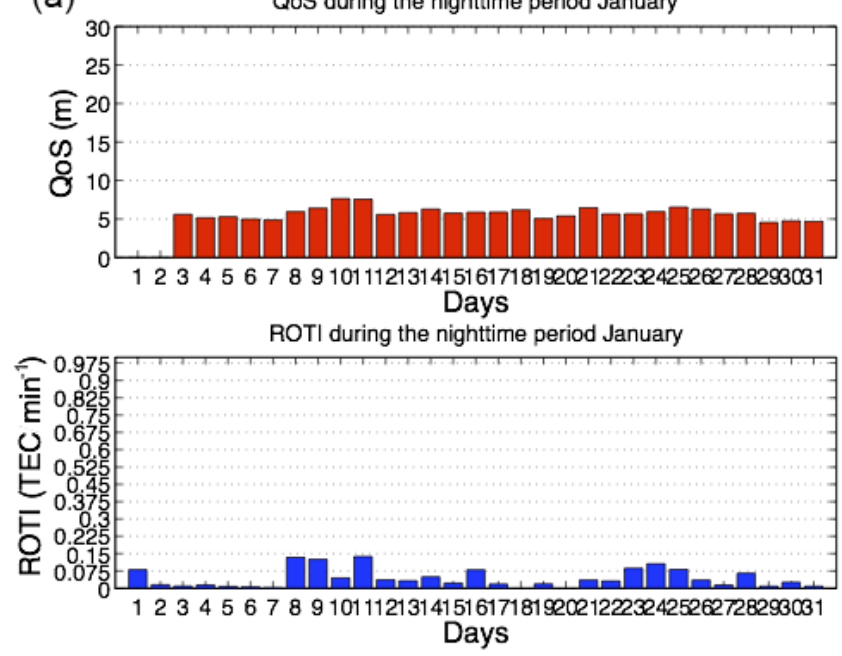

(b)
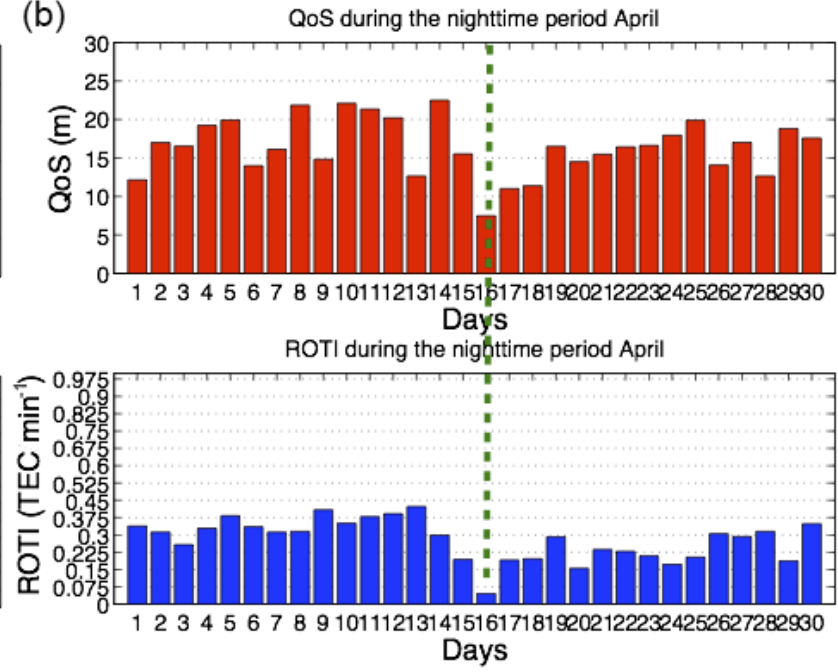

Figure 2. Correspondence of ionospheric irregularity inhibition with SBAS performance in January (left) and April (right) 2013.

the level of QoS is generally high (well above $10 \mathrm{~m}$ ) for the whole month except day 16, where the value of QoS is less than $10 \mathrm{~m}$. It is worth noting that 16 April is characterized by low (quiet) geomagnetic activities. The consequence of the plasma inhibition observed on 16 April is illustrated in the upper panel of Fig. 2, where the SBAS has a QoS value of $7.50 \mathrm{~m}$. More of the effects of the QoS are shown on the SBAS availability map and other SBAS outputs parameters in Figs. 4 and 5.

Figure 3 illustrates the correspondence of ionospheric plasma irregularities with the SBAS QoS performance indicator for the months of June (a characteristic month for June solstice) and October (a characteristic month of September equinox) 2013. It could be observed from the figure that the level of ionospheric plasma irregularities during the month of June is very low compared with October except 14 and 30 October. Days 14 and 30 October show another case of absence/lowering of ionospheric plasma irregularities like 16 April, which correspond to the low value of SBAS QoS (performance indicator) obtained in the centralwestern African low-latitude and equatorial region during equinoctial season. It worth noting also that these days in the month of October fall into the period of geomagnetically disturbed/unsettled conditions with the geomagnetic Ap index of 18.1 and $13.0 \mathrm{nT}$ respectively. The SBAS performance shown through the QoS for these days is 5.12 and $5.50 \mathrm{~m}$ respectively. This indicates the lowest value of QoS for the month of October and shows a good performance of SBAS. The QoS values obtained during the lowered/inhibited plasma irregularities clearly show that suppression/inhibition of plasma irregularities favours spacebased navigation users like SBAS. This confirms the work of others (e.g Klobuchar et al., 2002; Huang et al., 2002; Bandyoadhayay et al., 1997; de Paula et al., 2007), who have seen significant contributions of ionospheric irregularities on navigation and communication and surveillance systems.

To concretize the effect of plasma irregularities on SBAS performance in the central-western African low-latitude region, the daily APV-1 availability map, user differential range error indicator (UDREi), open service availability map for signal in space, and map of position of dilution of precision for 14 and 15 October 2013 are presented in Figs. 4 and 5 , showing the level of service availability obtained during the absence and presence of plasma irregularities respectively. The system level of service on 14 October for both APV-1 and open service availability reached $99.9 \%$ of the time due to the absence of plasma irregularities at postsunset till midnight periods ( $\mathrm{ROTI}_{\text {diff }}$ and QoS are 0.008 TECu $\mathrm{min}^{-1}$ and $5.14 \mathrm{~m}$ respectively) as indicated in Fig. 3. More than 12 satellites monitored were used $99 \%$ of the time, and their UDREi is relatively low at about 5. Also the position dilution of precision was very small, ranging from 1.91 to $2.62 \mathrm{~m} 95 \%$ of the time. However, on 15 October, when plasma irregularities were present with the average ROTI diff $_{\text {of }} 0.372 \mathrm{TECu} \mathrm{min}^{-1}$, the QoS is $19.19 \mathrm{~m}$. The SBAS service level for both APV-1 (critical safety application) and open service operation could not exceed $50.0 \%$ and $20 \%$ availability respectively. Although their UDREi is relatively low as well $(\sim 6)$, fewer than 10 satellites monitored were used $99 \%$ of the time. This leads to the high value of the position dilution of precision ranges from 20.58 to $27.58 \mathrm{~m}$ $95 \%$ of the time and causes degradation to the SBAS performance. Having low values of UDREi is not sufficient to guarantee better SBAS performance. The position dilution of precision should be relatively low as well in order to have good performance of the SBAS. The same trend of the service level is observed in SBAS APV-1 and open service availability maps, UDREi and position dilution of precision in all 
(a)
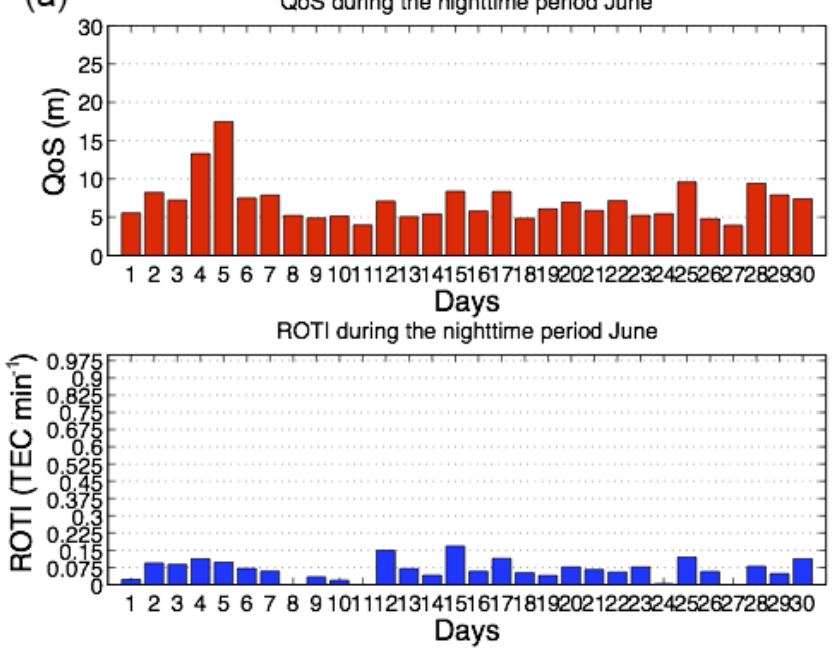

(b)
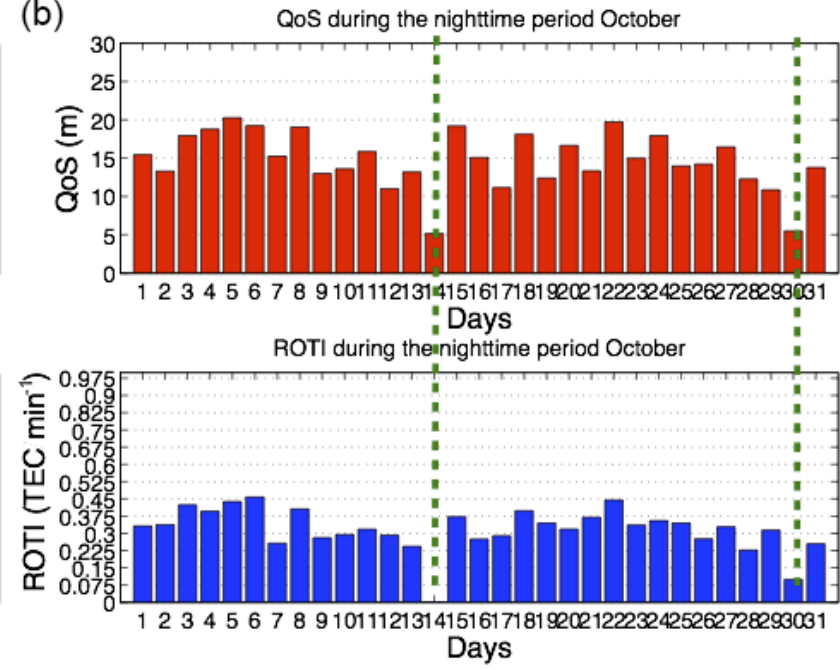

Figure 3. Correspondence of ionospheric irregularity inhibition with SBAS performance in June (left) and October (right) 2013.
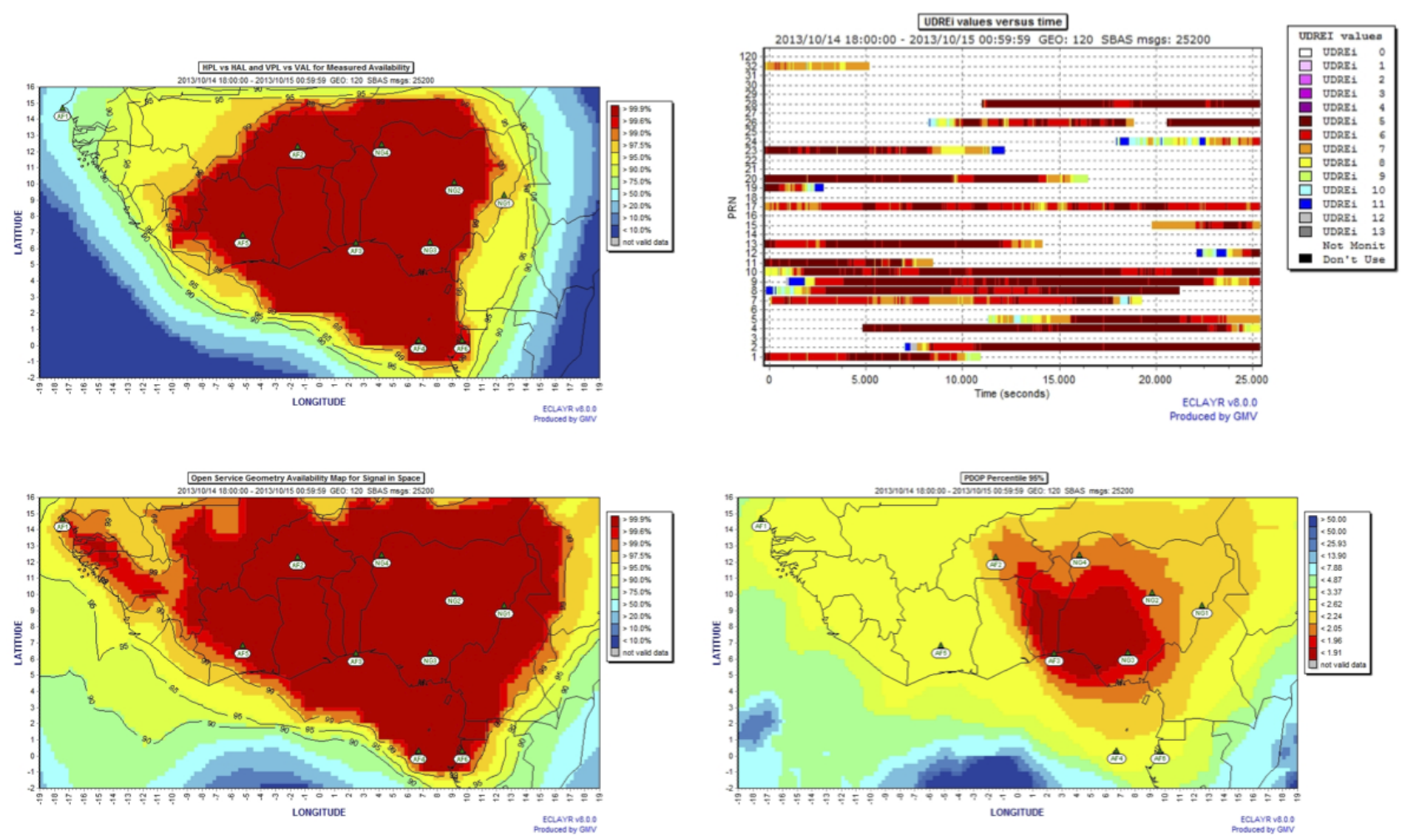

Figure 4. SBAS APV-1 availability map (upper left panel), user differential range error (UDREi) (upper right panel), open service geometry availability map for signal in space (lower left panel) and positional dilution of precision (lower right panel) for 14 October 2013 when irregularities were inhibited.

the days when the post-sunset plasma irregularities are inhibited or reduced. The service level reaches $99.9 \%$ of the time availability in a wider coverage service area. However, during the presence of ionospheric plasma irregularities, the level of service of APV-1 could not exceed $50.0 \%$ of the time availability in a very small service area. The inhibition ef- fect is quite visible on the SBAS performance with low QoS below $10 \mathrm{~m}$. This indicates good performance of the SBAS during the irregularity-inhibited periods.

In addition, Fig. 6 and Table 1 present the summary of the plasma irregularity-inhibited/reduced days for the period of strong occurrences of plasma ionospheric irregularities 

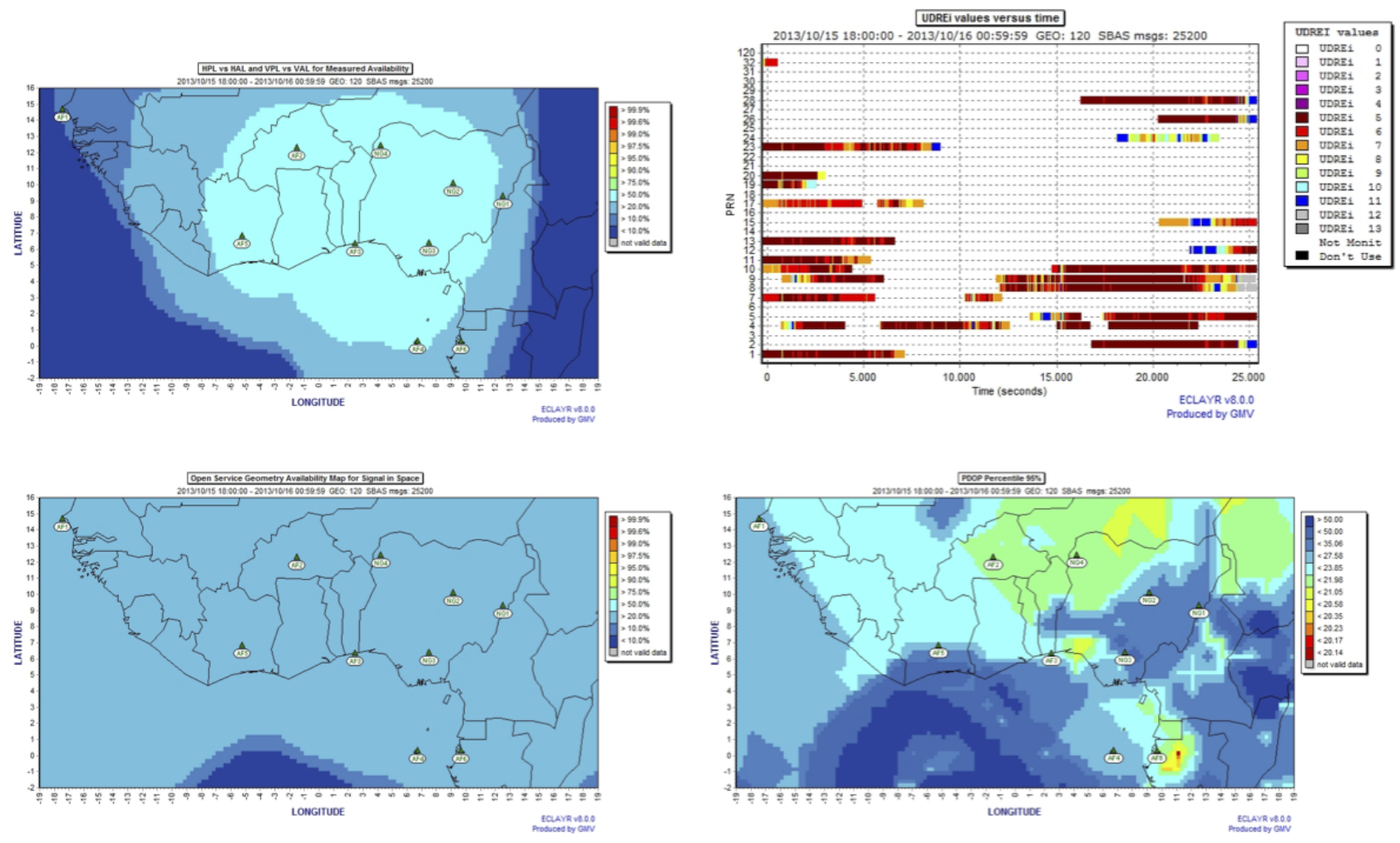

Figure 5. SBAS APV-1 availability map (upper left panel), user differential range error indicator (UDREi) (upper right panel), open service geometry availability map for signal in space (lower left panel) and positional dilution of precision (lower right panel) for 15 October 2013 when irregularities were not inhibited.

during two well-known equinoctial periods and the transition months to equinoctial periods (February and August), as well as transition periods from equinoctial months (May and November) of the year 2013, with their correspondence SBAS QoS over the region considered. It is clearly seen from the figure that seasons affect plasma ionospheric inhibition. Out of the 15 cases of plasma irregularity inhibition considered in this study, 5 cases are observed in March equinoctial season: 4 of them occurred during the disturbed conditions and only 1 case occurred during quiet conditions. However, during the June solstice, the number of cases recorded for ionospheric plasma inhibition is four, and all of them occurred during quiet conditions. In September equinoctial season, two cases were considered inhibited: one in quiet conditions and the other during the disturbed conditions. However during December solstice, four cases were observed as well: three during the quiet conditions and one in disturbed conditions. From the results, it is quite evident that ionospheric plasma irregularities are inhibited more in disturbed conditions than in quiet conditions during the equinoctial seasons. However, in solstitial seasons, ionospheric plasma irregularities are inhibited more during the quiet conditions.

In the same vein, Fig. 7 illustrates the statistical analysis showing the interrelationship between ionospheric plasma irregularities as indicated by ROTI and the SBAS performance
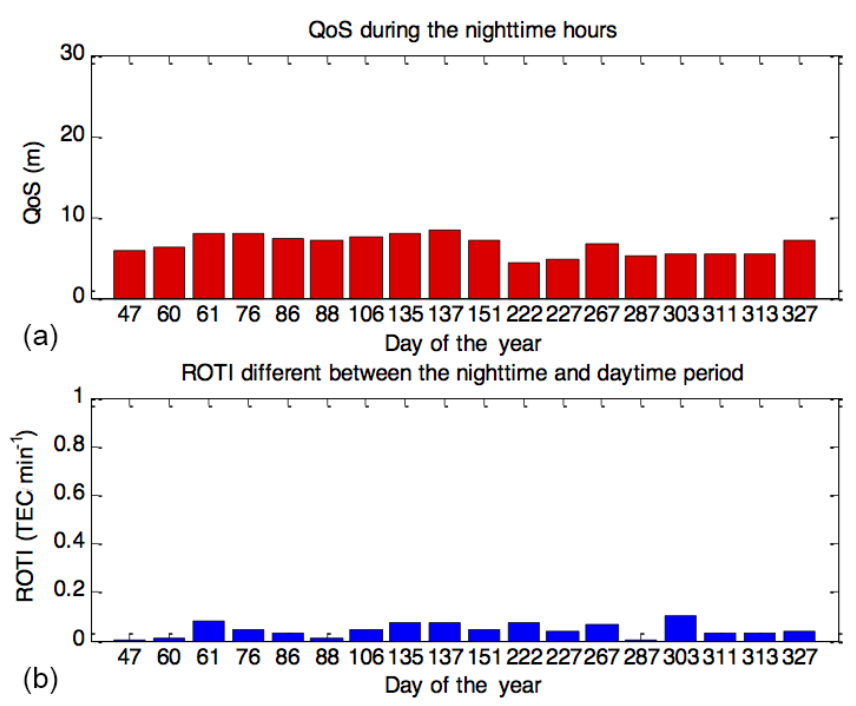

Figure 6. Summary of ionospheric irregularity-inhibited days with their correspondence SBAS QoS.

indicator (QoS) for the months of February, March, April, May, August, September, October and November of year 2013 , the period of the study. The value of correlation coefficient $(R, 79 \%)$ indicates a good interdependent relationship 


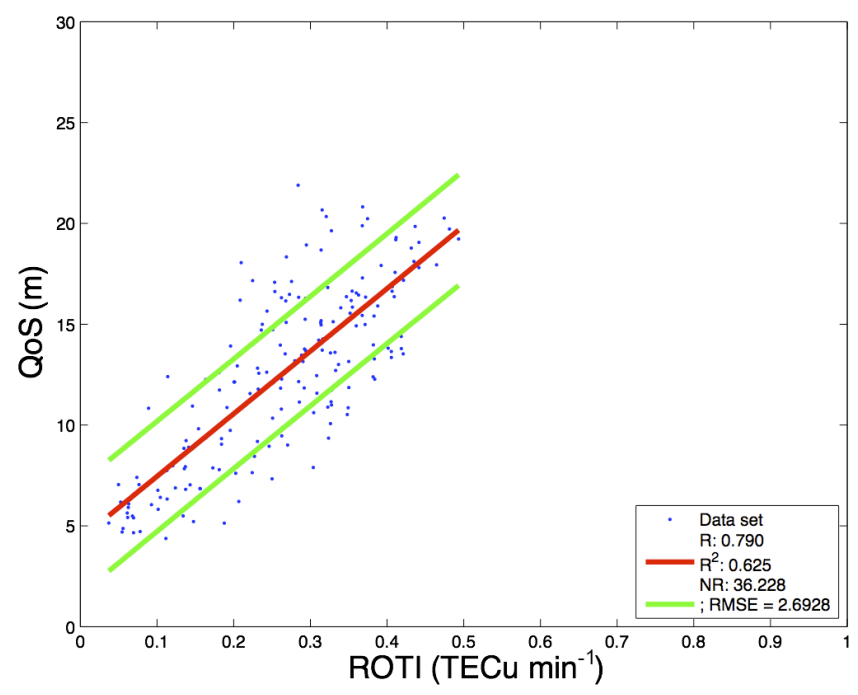

Figure 7. Interrelationship of ionospheric plasma irregularities and SBAS performance for the months of February, March, April, May, August, September, October and November of year 2013.

between the ionospheric plasma irregularities and SBAS performance. Also the coefficient of determination $\left(R^{2}, 62.5 \%\right)$ signifies that $62.5 \%$ of the SBAS performance degradation during the nighttime could be directly accounted for by ionospheric plasma irregularities. At the same time, Fig. 8 shows the correlation analysis between the ROTI and QoS for the whole year (1 January-31 December) of 2013. When combing the period of strong ionospheric irregularities to the period of low ionospheric irregularities, the value of $R$ for the period of strong ionospheric irregularities decreases to $75 \%$, while the $R^{2}$ decreases to $56.2 \%$. Including the period of low values of ROTI, Fig. 8 gives the correlation analysis of the ionospheric plasma irregularities and the SBAS performance indicator for the year 2013. These results confirm the ionospheric plasma irregularity occurrence during the post-sunset to post-midnight hours at the low-latitude and equatorial regions and give an indication that an SBAS would be severely affected in the region during those periods.

\section{Conclusions}

This paper investigates the signature of plasma irregularities on SBAS performance in the central-western African equatorial and low-latitude region. The main conclusions of the study are the following. (1) SBAS always performs better when the ionospheric plasma irregularities are less active: in solstice seasons, the performance of SBAS could be better during the geomagnetically quiet conditions compared with disturbed conditions, whereas in equinoctial seasons, SBAS may perform better during the geomagnetically disturbed conditions compared with quiet one. (2) Ionospheric plasma irregularities are reduced or inhibited more in disturbed con-

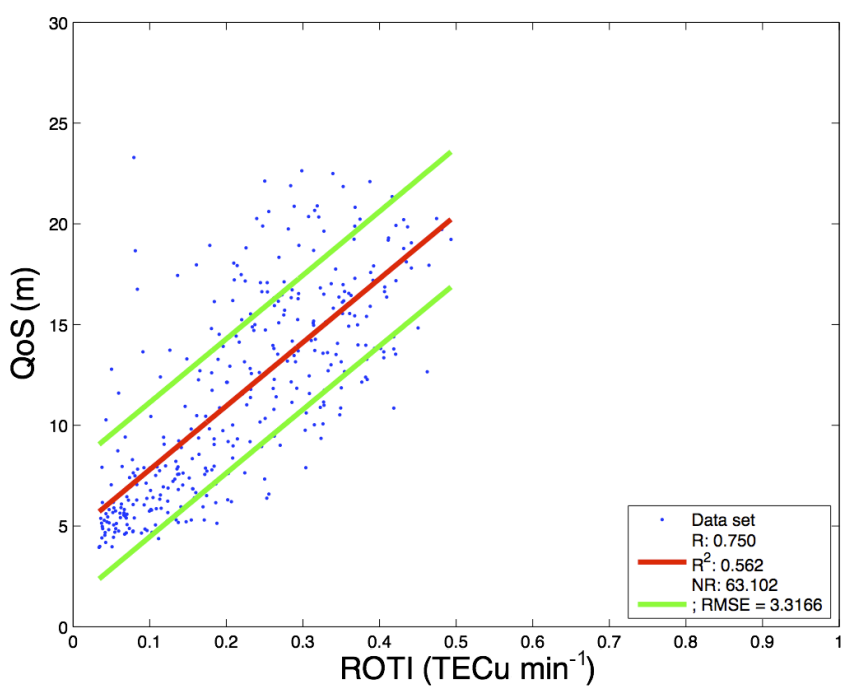

Figure 8. Interrelationship of ionospheric plasma irregularities and SBAS performance for the whole year (1 January-31 December) 2013.

ditions than in quiet conditions during equinoctial seasons. Also ionospheric plasma irregularities are reduced or inhibited more in geomagnetically quiet conditions than disturbed conditions during solstitial seasons. (3) Plasma irregularities contribute greatly to the nighttime degradation of the SBAS performance in the African equatorial and low-latitude regions and during equinoctial periods; $62.5 \%$ of nighttime degradation could be associated with ionospheric plasma irregularities over the region. (4) In the absence of plasma irregularities, the SBAS service level of $99.9 \%$ of the time availability for both critical safety operation (APV-1) and open service could be obtained in the western African equatorial and low-latitude region if proper tuning of the present EGNOS algorithm were considered.

Though the statistics are so limited in a way due to the few days used, more statistics could establish and affirm the proposition that inhibition is related to the phenomenon of geomagnetically disturbed conditions. However, the results obtained seem to provide convincing evidence that the ionospheric irregularity inhibition is more of disturbed conditions during the equinoctial seasons. Also the presence of plasma irregularities reduces the number of satellites in view; this leads to the increase of the positional dilution of precision and consequentially degrades the optimum performance of SBAS in low-latitude regions. More work could still be done using GNSS multi-constellations to access the potential improvement on the SBAS performance in the region during the presence of ionospheric plasma irregularities to consolidate the results obtained. 


\section{Data availability}

The data used for this work are obtained from the publicly available ground-based GNSS stations of International GNSS Services network (https://igscb.jpl.nasa.gov/ network/netindex.html), AFREF (http://www.afrefdata.org), NIGNET (www.nignet.net) and SONEL (http://www.sonel. org/-GPS-.html?lang=en).

Acknowledgements. The authors are grateful to the European Commission for sponsoring the Training EGNOS-GNSS in Africa (TREGA) project, a project dedicated to training through research, with this article being one of the outputs. The authors also thank the editor, associate editor and all the anonymous reviewers for their objective assessment of the paper and their valuable suggestions.

The topical editor, Kazuo Shiokawa, thanks three anonymous referees for help in evaluating this paper.

\section{References}

Abdu, M. A., Bittencourt, J. A., and Batista, I. S.: Magnetic declination control of the equatorial $\mathrm{F}$ region dynamo electric field development and spread F, J. Geophys. Res., 86, 11443-11446, 1981.

Abe, O. E, Rabiu, A. B., and Adeniyi, J. O.: Variability of $f(0) \mathrm{E}$ in the equatorial ionosphere with solar activity, Adv. Space Res., 51, 69-75, 2013.

Basu, S., Grove, K. M., Quinn, J. M., and Doherty, P.: A Comparison of TEC Fluctuation and Scientillation at Ascension Island, J. Atmos. Sol.-Terr. Phys., 61, 1219-1226, 1999.

Bhattacharya, S., Purohit, P. K., Tiwari, R., and Gwal, A. K.: Study of GPS based ionospheric scintillation and its effect on dual frequency receiver, J. Eng. Sci. Manage. Edu., 1, 55-61, 2010.

Cezón, A., Cueto, M., Ramírez, E., Ostorlaza, J., Izquierdo, V., Pérez, D., and Sardón, E.: GMV, SBAS performance Analysis in Equatorial Regions, ION-GNSS, 2014.

Chandran, H. and Rastogi, R. G.: Equatorial spread F over solar cycle, Ann. Geophys., 28, 709-716, 1972.

de Paula, E. R., Kherani, E. A., Abdu, M. A., Batista, I. S., Sobral, J. H. A., Kantor, I. J., Takahashi, H., de Rezende, L. F. C., Muella, M. T. A. H., Rodrigues, F. S., Kinter, P. M., Ledvina, B. M.,Mitchell, C. N., and Groves K. M.: Characteristics of the ionospheric F-region plasma irregularities over Brazilian longitudinal sector, Ind. J. Rad. Spa. Phys., 36, 268-277, 2007.

Fejer, B. G. and Kelley, M. C.: Ionospheric irregularities, Rev. Geophys., 18, 401-454, doi:10.1029/RG018i002p00401, 1980.

Fejer, B. G., Scherliess, L., and de Paula, E. R.: Effects of the vertical plasma drift velocity on the generation and evolution of equatorial spread F, J. Geophys. Res., 104, 19859-19869, 1999.

Handerson, S. B., Swenson, C. M., Chritensen, A. B., and Paxton, L. J.: Morphology of the equatorial anomaly and equatorial plasma bubbles using image subspace analysis of Global Ultraviolet Imager data, J. Geophys. Res., 110, A11306, doi:10.1029/2005JA011080, 2005.

Huang, C. Y., Burke, W. J., Machuzak, J. S., Gentile, L. C., and Sultan, P. J.: Equatorial plasma bubbles observed by DMSP satellites during a full solar cycle: toward a global climatology, J. Geophys. Res., 107, A12, doi:10.1029/2002JA009398, 2002.

ICAO: Procedures for Air Navigation Services: Air Traffic Management, Doc 4444, 14th Edn., 2001.

Jiyun, L., Pullen, S., Datta-Baruna, S., and Enge, P.: Assessment of Nominal Ionosphere Spatial Decorrelation for LAAS, IEEE/ION PLANS, 506-514, 2006.

Klobuchar, J. A., Doherty, P. H., Bakry El-Arini, M., Lejune, R., Dehel, T., de Paula, E. R., and Rodrigues, F. S.: Ionospheric issues for a SBAS in the equatorial region, IES2002, Alexandria, USA, 2005.

Lee, C., Liu, J. Y., Reinisch, B. W., Chen, W. S., and Chu, F. D.: The effect of prereversal drift, the EIA asymmetry, and magnetic activity on the equatorial spread $\mathrm{F}$ during solar maximum, Ann. Geophys., 23, 745-751, doi:10.5194/angeo-23-745-2005, 2005.

Manju, G., Devacia, C. V., and Sridharan, R.: On the seasonal variations of the threshold height for the occurrence of equatorial spread F during solar minimum and maximum year, Ann. Geophys., 25, 855-861, doi:10.5194/angeo-25-855-2007, 2007.

Nava, B., Rodríguez-Zuluaga, J., Alazo-Cuartas, K., Kashcheyev, A., Migoya-Orué, Y., Radicella, S. M., Amory-Mazaudier, C., and Fleury, R.: Middle and low latitude ionosphere response to 2015 St. Patrick's Day geomagnetic storm, J. Geophys. Res., Special issue on Big Storms, 2016.

Nishioka, M. A., Saito, A., and Tsugawa, T.: Occurrence characteristics of plasma bubbles derived from global groundbased GPS receiver networks, J. Geophys. Res., 113, A05301, doi:10.1029/2007JA012605, 2008.

Ouattara, F., Gnabahou, D. A., and Amory-Mazaudier, C.: Seasonal, Diurnal, and Solar-Cycle Variations of Electron Density at Two West Africa Equatorial Ionization Anomaly Stations, Int. J. Geophys., 1-9, doi:10.1155/2012/640463, 2012.

Pandya, N., Gran, M., and Paredes, E.: WAAS Performance Improvement with a new Undersampled ionospheric gradient threat model metric, Proceedings of the 2007 National Technical Meeting of the Institute of Navigation, San Diego, CA, 2007.

Perkins, F. W.: Ionospheric irregularities, Rev. Geophys., 13, 884 pp., 1975.

Pi, X., Mannucci, A. J., Lindqdwister, U. J., and Ho, C. M.: Monitoring of Global Ionospheric Irregularities using the worldwide GPS, Geophys. Res. Lett., 24, 2283-2286, doi:10.1029/97GL02273, 1997.

Rama Rao, P. V. S., Gopi, S., Krishna, K., Niranjan, K., and Prasad, D. S. V. V. D.: Study of Spatial and Temporal Characteristics of L-Band Scintillations over the Indian Low-Latitude Region and Their Possible Effects on GPS Navigation, Ann. Geophys., 24, 1567-1580, doi:10.5194/angeo-24-1567-2006, 2006.

Sarma, A. D., Prasad, N., and Madhu, T.: Investigation of suitability of grid-based ionospheric models for GAGAN, Electron. Lett., 42, 478-479, doi:10.1049/el:20063036, 2006.

Sarma, A. D., Venkata Ratnam, D., and Krishna Reddy, D.: Modelling low latitude ionosphere using modified planar fit method for GAGAN, IET Radar Sonar Navig., 3, 609-619, doi:10.1049/iet-rsn.2009.0022, 2009.

Seo, J., Walter T., and Enge, P.: Availability Impact on GPS Aviation Due to Strong Ionospheric Scintillation, IEEE T. Aero. Elec. Sys., 47, 1963-1973, 2011. 
Sparks, L., Blanch, J., and Pandya, N.: Estimating ionospheric delay using Kriging: 1. Methodology, Radio Sci., 46, RSOD21, doi:10.1029/2011RS004667, 2011.

Stoneback, R. A. and Heelis, R. A.: Identifying equatorial ionospheric irregularities using in situ ion drift, Ann. Geophys., 32, 421-429, doi:10.5194/angeo-32-421-2014, 2014.

Sunda, S., Vyas, B. M., Satish, S. V., Khekale, P. V., and Parikh, K. S.: Improvement of position accuracy with GAGAN and the impact of scintillation on GNSS, Positioning, 4, 282-288, doi:10.4236/pos.2013.44028, 2013.

Suryanarayana Rao, K. N.: GAGANThe Indian satellite based navigation system, Indian J. Radio Sci. Phys., 36, 293-302, 2007.

Tanna, H. J., Karia, S. P., and Pathak, K. N.: A study of L band scintillations during the initial phase of rising solar activity at an Indian low latitude station, Adv. Space Res., 52, 412-421, 2013.

Tsunoda, R.: Control of the seasonal and longitudinal occurrence of equatorial scintillations by the longitudinal gradient in integrated E region Pedersen conductivity, J. Geophys. Res., 90, 447-456, doi:10.1029/JA090iA01p00447, 1985.
Venkata Ratnam, D., Sujatha, C. H., Sarma, A. D., and Ravindran, S.: Modelling of GAGAN TEC data using spherical harmonic functions, paper presented at International Conference on Computers and Devices for Communication, Inst. Electr. Electron. Eng., Kolkota, India, 14-16 December, 2009.

Venkata Ratnam, D., Sarma, A. D., Satya Srinivas, V., and Sreelatha, P.: Performance evaluation of selected ionospheric delay models during geomagnetic storm conditions in low-latitude region, Radio Sci., 46, RS0D08, doi:10.1029/2010RS004592, 2011.

Walter, T., Rajagopal, S., Datter-Barua, S., and Blanch, J.: Protecting Against Unsampled Ionospheric Threat, Proceeding of Beacon Satellite Symposium, Trieste, Italy, 2004.

Zoundi, C., Ouattara, F., Fleury, R., Amory-Mazaudier, C., and Lassudrie Duchesne, P.: Seasonal TEC Variability in West Africa Equatorial Anomaly Region. European Journal of Scientific Research, EuroJournals, 77, 309-319, 2012. 